\title{
RIP CURRENT FATALITIES ON THE BLACK SEA BEACHES OF ISTANBUL AND EFFECTS OF WINDS
}

\author{
Baris Barlas ${ }^{1}$ and Serdar Beji ${ }^{2}$
}

\begin{abstract}
This study investigates fatalities due to rip currents on the Black Sea coast of Istanbul. Results include the incidence rate of fatalities from rip currents, their causes, temporal and spatial distributions. The data shows that, nearly $70 \%$ of all drowning fatalities are associated with rip currents, and that on the average 33 people reportedly die from rip currents each year in Istanbul Black Sea coast. Thus, considering the wind speeds versus rip current fatalities, about one third of the fatalities occur when the wind speed is between 1.5-2.0 m/s. For the wind speeds 1.0-1.5 m/s the rip current magnitude is not too intense so people consider themselves capable enough to swim but for poor swimmers this is the most dangerous case. Nearly $60 \%$ of the fatalities in this wind speed interval is found to be children.
\end{abstract}

Keywords: rip currents; fatalities; Black Sea

\section{INTRODUCTION}

There are numerous articles in the literature regarding rip currents, their formation, and related incidents. Gensini and Ashley (2010) analyze fatalities caused by rip currents in the United States between the period 1994-2007. Sherker et al. (2010) assess the beliefs and behaviors of Australian beachgoers in relation to beach flags and rip currents. Miloshis and Stephenson (2011) suggest rip current escape strategies as "do nothing" and "swim parallel to the beach". In particular, they indicate that, of the two methods doing nothing and allowing the rip current to take a swimmer is the most effective strategy. Morgan et al. (2009) analyze drowning risk factors at surf beaches in Australia. Chandramohan et al. (1997) investigate the rip current zones along the beaches in Goa, India. Sabet and Barani (2011) present a field investigation of rip currents along the southern coast of Caspian Sea. Barlas and Beji (2016) investigates rip current fatalities on the Black Sea beaches of Istanbul and effects of cultural aspects in shaping the incidents.

On the rip current formation and its physical background Dalrymple et al. (2011) give a comprehensive review on field measurements, instrumentation, laboratory techniques, and numerical modeling of rip currents. Kumar et al. (2011) use a 3D numerical ocean model for surf zone applications using examples of rip current formation in longshore bar. Orzech et al. (2011) investigate the formation of megacusps on rip channel bathymetry. The relationship between alongshore rip channel migration and sediment transport is investigated using time-averaged video images to identify the positions of rip channels by Orzech et al. (2010). Thiebot et al. (2012) analyze the influence of wave direction on the morphological response of a double sandbar system, and interactions between the patterns in the two shore-parallel bars.

In this study, for 380 drowning cases between 2007 and 2013, the incidence rates, rate of fatalities from rip currents, their causes, and spatial distributions, and their relation to atmospheric events are analyzed. The aim of this work is to investigate rip currents fatalities in the gendarmerie region of Istanbul Black Sea coast, and to form a framework of the fatal rip currents so that when the beachgoers fit in risk window, extra precautions can be taken in order to minimize the occurrence of drownings and related fatalities.

\section{CHARACTERISTICS OF RIP CURRENTS}

Rip currents are a common occurrence on many beaches. A rip current is a powerful and separate seaward current that can flow over $2.4 \mathrm{~m} / \mathrm{s}$ running perpendicular to the beach, out into the sea (Bowen and Inman, 1969). In general, the speeds of rip currents are between 0.3 to $1.5 \mathrm{~m} / \mathrm{s}$ (Basco, 1983; Miloshis and Stephenson, 2011). Compared to $800 \mathrm{~m}$ freestyle world record in swimming, which is nearly $1.8 \mathrm{~m} / \mathrm{s}$, the speed of the rip currents is quite high. When a swimmer is caught in a $\mathrm{rip}$, he/she is pulled offshore. If the swimmer is inexperienced, he/she attempts to swim back to shore against the rip current and consequently becomes tired of struggling, suffers exhaustion, fears, and eventually panics. In the end, as a result of wasted efforts the swimmer may be drown.

\footnotetext{
${ }^{1}$ Department of Naval Arch. \& Marine Engineering, Istanbul Technical University, Istanbul, Turkey

${ }^{2}$ Department of Ocean Engineering, Istanbul Technical University, Istanbul, Turkey
} 
The existence of rip currents depends on the beach bathymetry, wind direction and speed, wave height and wave period, the form of the beach, physical structures at the beach, and the sand (Bowen, 1969; Lyons, 1991; Dalrymple et al., 2011). The rip currents may extend 50 to 300 meters lengthwise, and 6 to 30 meters wide (Short and Hogan, 1994). The nearshore bathymetry is probably the most important factor in the formation of rip currents. A bar-trough-bar type bottom configuration is almost a trademark of a rip current (Hansen and Svendsen, 1986).

The offshore directed rip currents interact with the incident waves to produce a negative feedback on the wave forcing, hence to reduce the strength and offshore extent of the currents. The two physical processes arising from refraction by currents, bending of wave rays and changes of wave energy, are both found to be important. The onset of instabilities of circulations occurs at the nearshore region where rips are "fed" rather than offshore at rip heads with no wave-current interaction. The incident wave height has some effects on the strength and offshore extent of rip currents, but these are rather weak compared to the effects of rip channel spacing and depth (Yu and Slin, 2003). Once the waves are high enough to break over the top of the bar the question of how high becomes relatively unimportant. Since wave breaking over a bar is primarily dictated by water depth, it is a sufficient condition for breaking to get wave heights comparable or greater than the water depth over the bar. If the bar is shallow the required wave height for breaking is smaller (Haller and Dalyrymple, 1999). The process is basically determined by the ratio of water depth to wave height and is a relative quantity. The formation of offshore directed rip currents is depicted in Figure 1. On the other hand, the depth of the trough across which the rip flows offshore is quite an important parameter in determining the strength of the rip current. In principle the deeper the channel the stronger the current is. Rip currents are usually observed in the aftermath of a storm or windy weather conditions if the wind blows from a favorable direction to generate sufficiently high waves advancing perpendicular to the beach. Atmospheric conditions are therefore another crucial factor in the formation of rip currents. Average bottom slope in the nearshore region is also observed to influence the current strength by dictating the rate of change of shoaling. Gradual shoaling over long distances or a mild-slope type bathymetry gives rise to stronger currents (Arthur, 1962). Finally, the fine sand in the beach is increasing the probability of rip current formations, while coarse sand or pebble beaches are decreasing the probability (Pfaff, 2003).

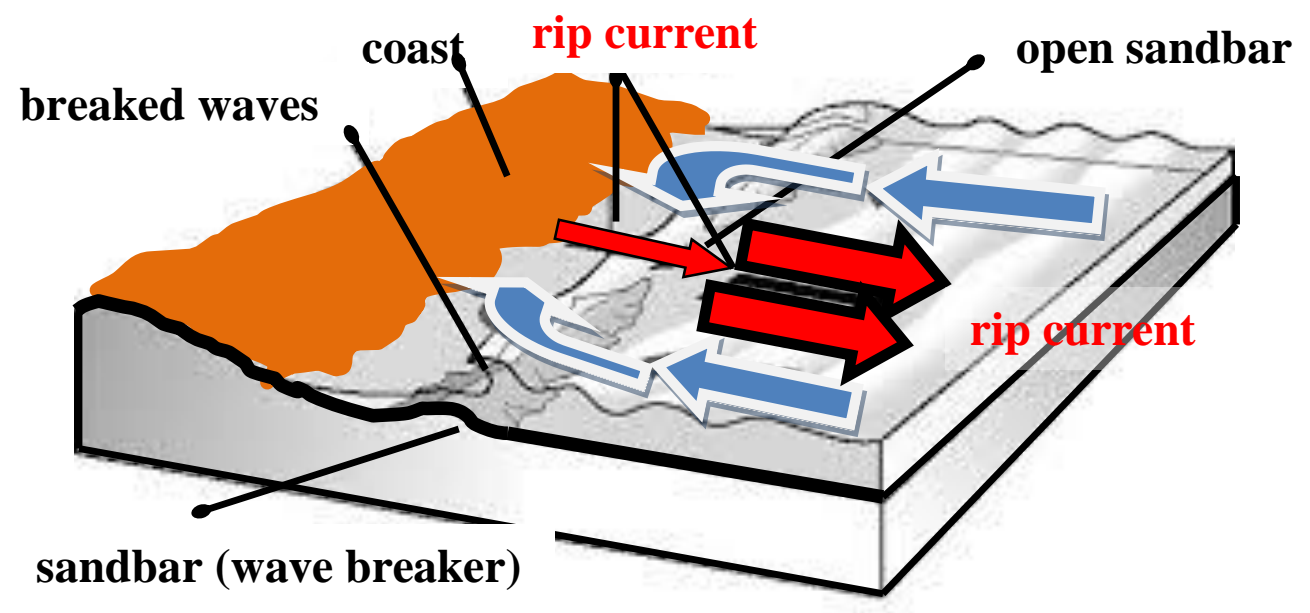

Figure 1. Rip current formation.

\section{ISTANBUL BLACK SEA COAST RIP CURRENT INCIDENTS}

This study examines fatalities due to rip currents in the gendarmerie region of the Black Sea coasts of Istanbul during the period of 2007-2013. Istanbul, being the largest city in Turkey with a population over 15 million, has nine known beaches, four in the European and five in the Asian 
gendarmerie region of the Black Sea coasts. The total length of the gendarmerie region beach coastline is approximately $153 \mathrm{~km}$ (92 km in European side and $61 \mathrm{~km}$ in Asian side); the coastline length of popular beaches is approximately $57 \mathrm{~km}$ (30 km in European side and $27 \mathrm{~km}$ in Asian side) (Figure 2). The Istanbul Gendarmerie Command's hazard event records are examined to classify rip current fatalities on the Black Sea beaches of Istanbul during the period of 2007-2013. The data contains the drownings recorded only in the gendarmerie region of Istanbul. The Gendarmerie regions are rural areas, generally outside of towns with sparse inhabitants. Reaching these areas from the densely populated regions takes on average around one hour. The beaches are free of charge, without parking fees, on some beaches there are no life guards on duty. Drowning reports are made only for deaths and serious non-fatal drownings. The reported rip-related drowning fatalities are given in Table 1. Gendarmerie hazard event records show that $68 \%$ of all drowning fatalities are associated with rip currents and that on average 33 people die from rip currents each year on the Black Sea beaches of Istanbul. 54\% of fatalities are between the ages 18-35 years old. Difference in gender vulnerability is quite pronounced; males are nearly 7 times more likely to fall victim to a deadly rip current than females. Weekends naturally have more fatalities than any other day of the week. As expected, summer season weekends are observed to have more fatalities than any other time of the year. July is the most hazardous month, and is followed by August. The Muslim fasting month of Ramadan has a significant effect on reducing the fatalities with only 7 reported deaths during the period of 2007-2013 (Barlas and Beji, 2016). The reported rip-related drowning fatalities at month of Ramadan are given in Table 2.

\begin{tabular}{|l|l|l|l|}
\hline \multicolumn{4}{|c|}{ Table 1. Reported rip-related drowning fatalities. } \\
\hline Year & $\begin{array}{l}\text { Drowning } \\
\text { fatalities }\end{array}$ & $\begin{array}{l}\text { Rip } \\
\text { current } \\
\text { fatalities }\end{array}$ & $\begin{array}{l}\text { Percentage } \\
\text { of rip current } \\
\text { fatalities }\end{array}$ \\
\hline 2007 & 51 & 36 & $71 \%$ \\
2008 & 34 & 27 & $79 \%$ \\
2009 & 54 & 44 & $82 \%$ \\
2010 & 47 & 30 & $64 \%$ \\
2011 & 51 & 27 & $53 \%$ \\
2012 & 53 & 31 & $59 \%$ \\
2013 & 51 & 32 & $63 \%$ \\
Total & 341 & 227 & Avg. $67 \%$ \\
\hline
\end{tabular}

\begin{tabular}{|c|c|}
\hline Year & Rip current fatalities \\
\hline 2009 & 2 \\
\hline 2010 & 1 \\
\hline 2011 & 0 \\
\hline 2012 & 3 \\
\hline 2013 & 1 (Foreigner) \\
\hline Total & 7 \\
\hline
\end{tabular}

About $54 \%$ of fatalities happen to be between the ages 18-34 years old. The reported rip current fatalities by age groups are given in Figure 3. Unique differences in gender vulnerability have been found, males are nearly 5 times more likely to fall victim to a deadly rip current than females $(81 \%$ male vs $19 \%$ female). In Australia $76 \%$ of rip current fatalities are male (Miloshis ve Stephenson, 2011), in the US this ratio is $84 \%$ (Gensini ve Ashley, 2010).

Weekends are shown to have more fatalities than any other day of the week. Summer season weekends are observed to have more fatalities than any other time of the year. July is the most hazardous month, and is followed by August. 2/3 of rip current fatalities occur during 11:00-18:00 time interval. Reported rip current fatalities by accident times are given in Figure 4. 


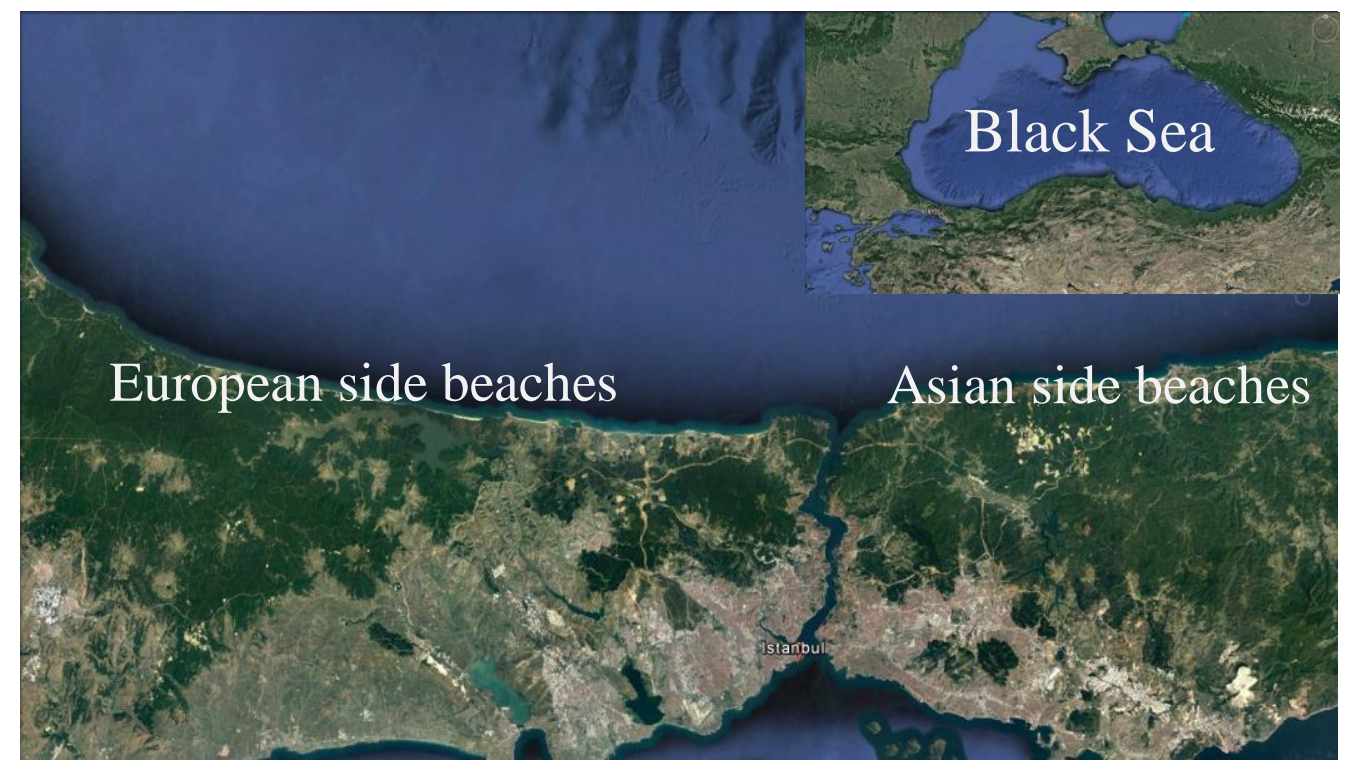

Figure 2. Istanbul Black Sea coast beaches.

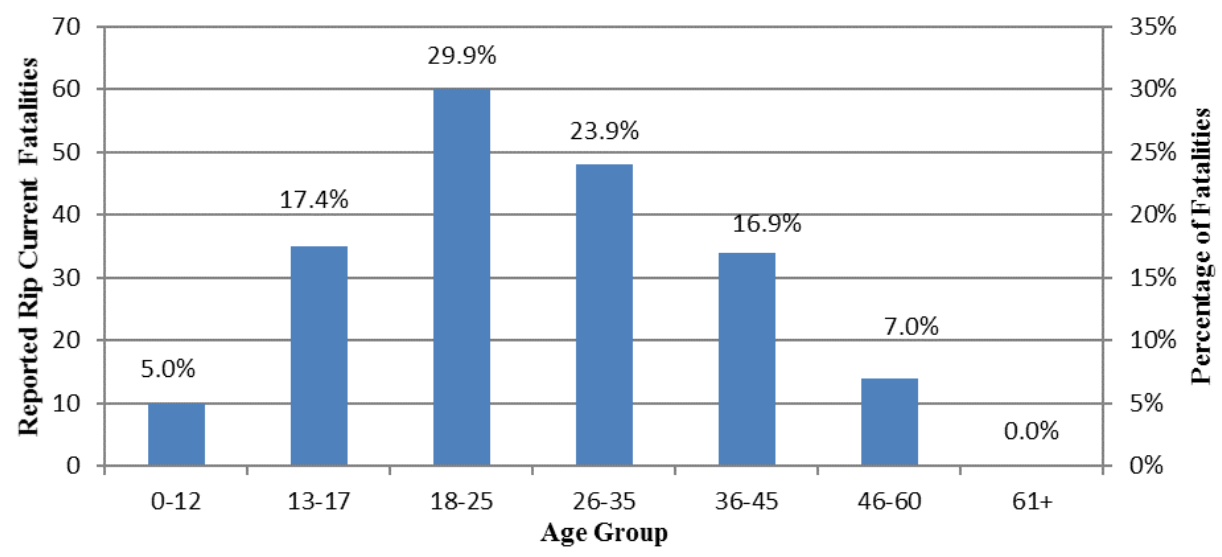

Figure 3. Reported rip current fatalities by age groups.

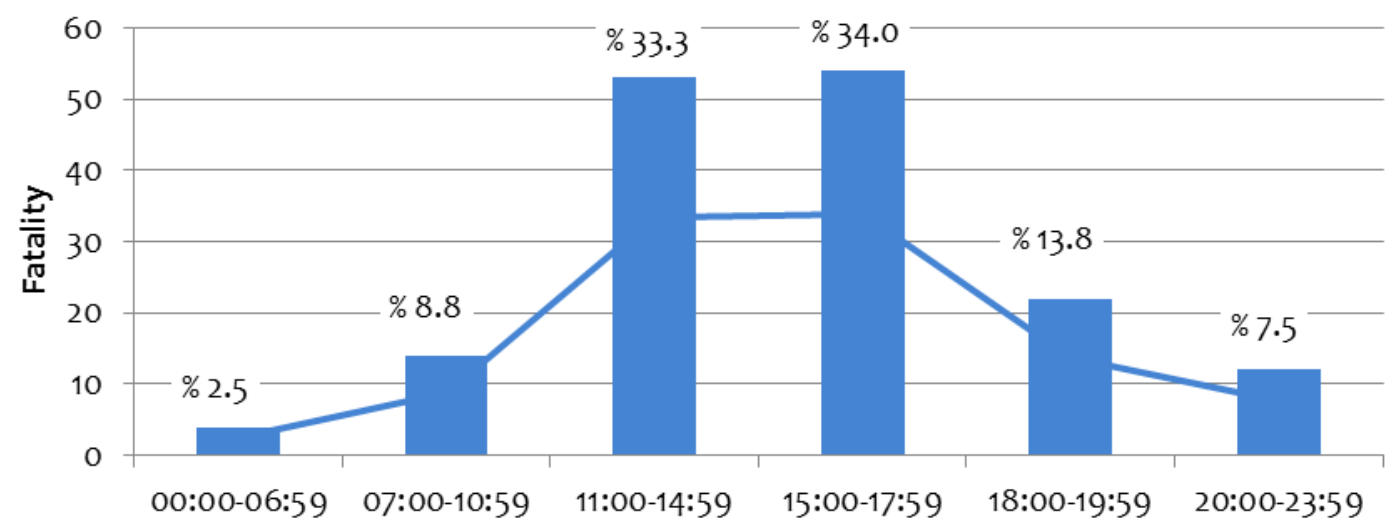

Figure 4. Reported rip current fatalities by accident time. 


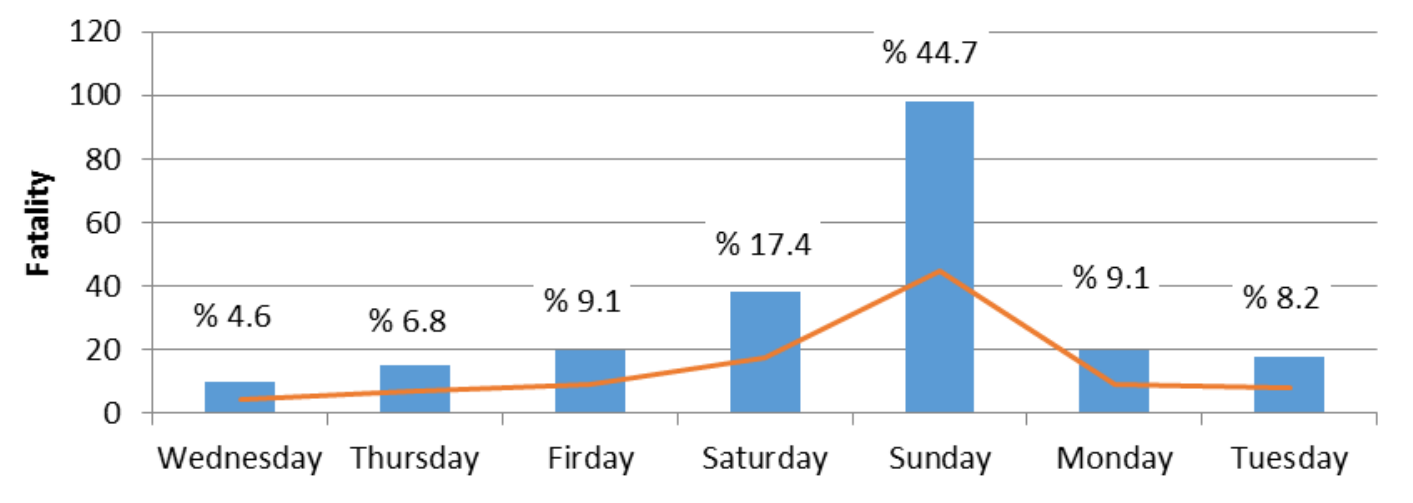

Figure 5 . Reported rip current fatalities by days of the week.

\section{EFFECTS OF WINDS}

Another relevant set of data was obtained from Turkish State Meteorological Service. This database includes atmospheric events, such as wind directions, and magnitudes. The fatality reports and meteorological data are considered together to get an insight into fatalities by first ascertaining whether the casualties were related to the rip currents or not, and then checking if a correlation can be established between the casualties and the atmospheric events. Fatality locations were mapped to depict the spatial distribution of fatal rip currents. On the day that a rip current fatality occurred, the atmospheric condition in relation to the beach was also indicated. Here, the wind data obtained from two different meteorological stations located in close proximity of the beaches, one station in European side and one station in Asian side. Thus, considering the wind speeds versus rip current fatalities, about one third of the fatalities occur when the wind speed is between $1.5-2.0 \mathrm{~m} / \mathrm{s}$ as shown in Table 3. When the wind speed is below $0.8 \mathrm{~m} / \mathrm{s}$, there are no rip current fatalities, simply because there are no rip currents. When the wind speed is greater than $4 \mathrm{~m} / \mathrm{s}$ the people do not go to the beaches because of very severe weather conditions. However, for the wind speeds $1.0-1.5 \mathrm{~m} / \mathrm{s}$ the rip current magnitude is not too intense, so people consider themselves capable enough to swim, but for poor swimmers this is the most dangerous case. Nearly $60 \%$ of the fatalities in this wind speed interval is found to be children. Precautions appropriate to the cultural background of the people are suggested to reduce downing incidents and related fatalities. The success of educational or informational activities in this region therefore requires much effort, especially when young adults are considered. Children are relatively easier to reach and they are more willing to listen to the warnings and obey the instructions. Therefore, it is expected that the brochures and billboards prepared in this context will be effective over the medium term by first educating children and youngsters. By using regression analysis, the wind speed vs fatality risk is introduced in Figure 6.

\begin{tabular}{|c|c|c|}
\hline \multicolumn{3}{|c|}{ Table 3. Reported rip current fatalities by wind speed. } \\
\hline Wind speed (m/s) & Rip current fatalities & Percentage \\
\hline$<1.0$ & 0 & $0.0 \%$ \\
$1.0-1.5$ & 22 & $17.2 \%$ \\
$1.5-2.0$ & 41 & $32.0 \%$ \\
$2.0-2.5$ & 21 & $16.4 \%$ \\
$2.5-3.0$ & 21 & $16.4 \%$ \\
$3.0-3.5$ & 20 & $15.6 \%$ \\
$3.5-4.0$ & 3 & $2.3 \%$ \\
$4+$ & 0 & $0.0 \%$ \\
\hline
\end{tabular}


Wind Speed vs Fatality Risk

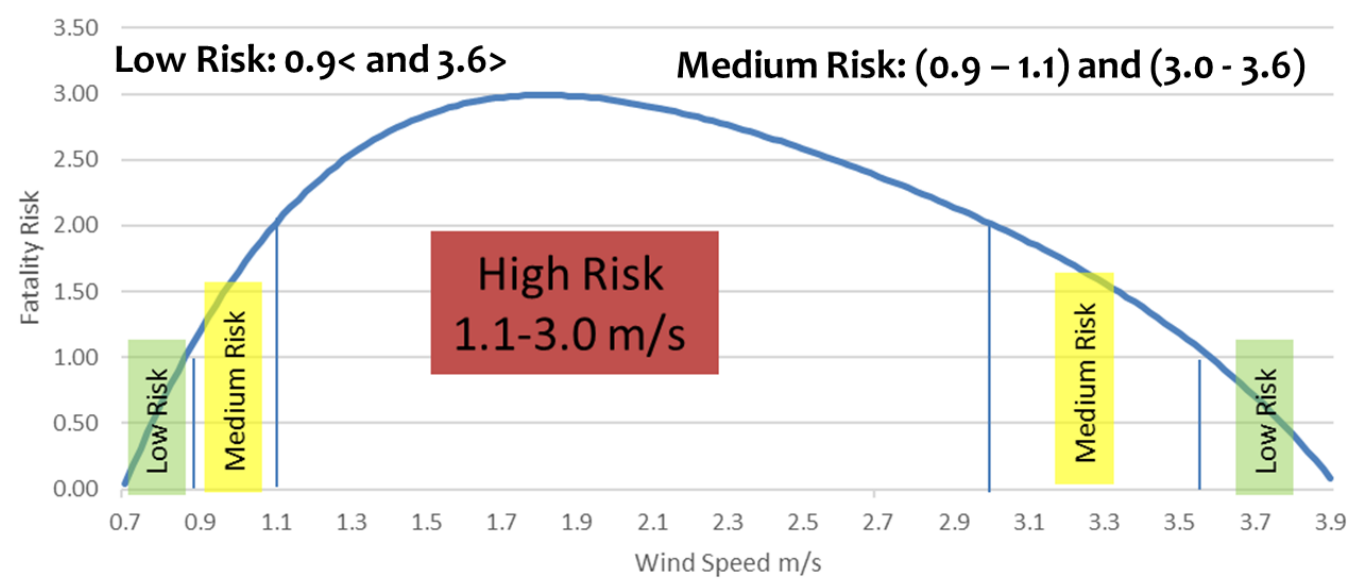

Figure 6. Istanbul Black Sea coast beaches wind speed vs fatality risk.

\section{CONCLUSIONS}

Records examined in this study suggest that, in the gendarmerie region of Istanbul Black Sea coast, about 33 people fall victim to rip currents each year. Such a high fatality rate indicates that the presence of rip currents is a serious danger even for good swimmers. The primary reasons for falling a victim may be enumerated as follows. Unawareness of the dangers of rip currents, and lack of good swimming skills. Ignoring the dangers by thinking "nothing happens to me, but if happens it is my business". Swimming in areas without lifeguards or swimming in areas with lifeguards but who cannot constantly monitor the number of people from various parts of a long coast line. People being pulled away from the safe shallow waters to the open sea panicking with fear and trying to return back to the coast, consequently getting too tired even to keep themselves on the water.

The wind data was obtained from two different meteorological stations located in close proximity of the beaches, Kumkoy in European side and Sile in Asian side. Thus, considering the wind speeds versus rip current fatalities, the highest percentage of fatalities are observed between wind speeds 1.1$3.0 \mathrm{~m} / \mathrm{s}$ while nearly one third of the fatalities are witnessed for the wind speeds between $1.5-2.0 \mathrm{~m} / \mathrm{s}$. When the wind speed is below $0.8 \mathrm{~m} / \mathrm{s}$, there are no rip current fatalities, simply because there are no rip currents. When the wind speed is greater than $4 \mathrm{~m} / \mathrm{s}$ the people do not go to the beaches because of very severe weather conditions. However, for the wind speeds $0.8-1.5 \mathrm{~m} / \mathrm{s}$ the rip current magnitude is not too intense, so people consider themselves capable enough to swim, but for poor swimmers this is the most dangerous case. Nearly $60 \%$ of the fatalities in this wind speed interval is found to be children.

\section{REFERENCES}

Arthur, R.S. 1962. A note on the dynamics of rip currents, Journal of Geophysical Research, 67(7), 2778-2779.

Barlas B., and S. Beji. 2016. Rip current fatalities on the Black Sea beaches of Istanbul and effects of cultural aspects in shaping the incidents, Natural Hazards, 80, 811-821.

Basco, D.R. 1983. Surf zone currents, Coastal Engineering, 7, 331-355.

Bowen, A.J., and Inman, D.L. 1969. Rip currents 2: Laboratory and field observations, Journal of Geophysical Research, 74, 5479-5490.

Bowen, A.J. 1969. Rip currents 1: Theoretical investigations, Journal of Geophysical Research, 74, 5468-5478.

Chandramohan P., V. Sanil Kumar, and B.K. Jena. 1997. Rip current zones along beaches in Goa, West Coast of India. Journal of Waterway Port Coastal and Ocean Engineering, 123(6), 322328.

Dalrymple, R.A., J.H. MacMahan, J.H.M. Reniers, and V. Nelko. 2011. Rip Currents, Annu. Rev. Fluid Mech., 43, 551-581. 
Gensini, V.A., and W.S. Ashley, 2010. An examination of rip current fatalities in the United States, Natural Hazards, 54, 159-175.

Haller, M.C., and R.A. Dalrymple. 1999. Rip current dynamics and nearshore circulation, Research Report CACR-99-05, Center for Applied Coastal Research, University of Delaware.

Hansen, J.B., and I.A. Svendsen. 1986. Experimental investigation of the wave and current motion over a longshore bar, Proceedings $20^{\text {th }}$ International Conference Coastal Engineering, 11661179.

Kumar, N., G. Voulgaris, and J.C. Warner. 2011. Implementation and modification of a threedimensional radiation stress formulation for surf zone and rip-current applications, Coastal Engineering, 58, 1097-1117.

Lyons, S., 1991. Rip Currents: Description, Observations and Theories, Cooperative Institute for Applied Meteorological Studies, Department of Atmospheric Sciences, Texas A\&M University.

Miloshis, M., and W.J. Stephenson. 2011. Rip current escape strategies: lessons for swimmers and coastal rescue authorities, Natural Hazards, 59, 823-832.

Morgan, D., J. Ozanne-Smith, and T. Triggs. 2009. Self-reported water and drowning risk exposure at surf beaches, Aust N Z J Public Health, 33,180-188.

Orzech, M.D., E.B. Thornton, J.H. MacMahan, W.C. O'Reilly, and T.P. Stanton. 2010. Alongshore rip channel migration and sediment transport, Marine Geology, 271, 278-291.

Orzech, M.D., J.H.M. Reniers, E.B. Thornton, and J.H. MacMahan. 2011. Megacusps on rip channel bathymetry: Observations and modeling, Coastal Engineering, 58, 890-907.

Pfaff, S. 2003. Rip Current Forecasting, WFO MHX Coastal and Marine Conference, Morehead City, NC, USA.

Sabet, B.S., and G.A. Barani. 2011. Field investigation of rip currents along the southern coast of the Caspian sea, Scientia Iranica A, 18(4), 878-884.

Sherker, S., A. Williamson, J. Hatfield, R. Brander, and A. Hayen. 2010. Beachgoers' beliefs and behaviours in relation to beach flags and rip currents, Accident Analysis and Prevention, 42, $1785-1804$.

Short, A.D., and C.L. Hayen. 1994. Rip currents and beach hazards: Their impact on public safety and implications for coastal management, Journal Coastal Research, Special Issue 12, 197-209.

Thiebot, J., D. Idier, R. Garnier, A. Falques, and B.G. Ruessink. 2012. The influence of wave direction on the morphological response of a double sandbar system, Continental Shelf Research, $32,71-85$.

Yu, J., and D.N. Slinn. 2003. Effects of wave-current interaction on rip currents, Journal of Geophysical Research, 108(C3), 3088, doi:10.1029/2001JC001105. 